\title{
Tumor suppressor microRNA-136-5p regulates the cellular function of renal cell carcinoma
}

\author{
PEIJIE CHEN ${ }^{1-3^{*}}$, LIWEN ZHAO $^{1,3^{*}}$, XIANG PAN $^{1}$, LU JIN $^{1,3}$, CANBIN LIN $^{1-3}$, WEIJIE XU $^{1}$, JINLING XU $^{1}$,

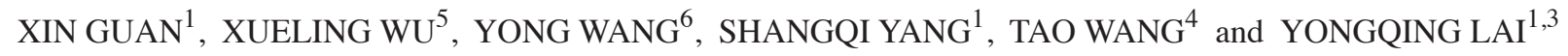 \\ ${ }^{1}$ Department of Urology, Peking University Shenzhen Hospital, Shenzhen, Guangdong 518036; \\ ${ }^{2}$ Department of Urology, Shantou University Medical College, Shantou, Guangdong 515041; \\ ${ }^{3}$ The Guangdong and Shenzhen Key Laboratory of Male Reproductive Medicine and Genetics, \\ Peking University Shenzhen Hospital, Institute of Urology of Shenzhen PKU-HKUST Medical Center; \\ ${ }^{4}$ Department of Cardiovascular Surgery, Peking University Shenzhen Hospital, Shenzhen, Guangdong 518036; \\ ${ }^{5}$ Department of Urology, Longgang District Central Hospital of Shenzhen, Shenzhen, Guangdong 518116; \\ ${ }^{6}$ Department of Reproduction, Peking University Shenzhen Hospital, Shenzhen, Guangdong 518036, P.R. China
}

Received April 30, 2017; Accepted December 11, 2017

DOI: $10.3892 / \mathrm{ol} .2018 .8081$

\begin{abstract}
MicroRNAs (miRs) are involved in diverse physiological and developmental processes at the post-transcriptional level in cells. Previous studies have demonstrated that miR-136-5p is involved in certain types of cancer. However, the function of miR-136-5p in renal cell carcinoma (RCC) remains to be fully elucidated. In present study, miR-136-5p expression levels were determined by reverse transcription-quantitative polymerase chain reaction (RT-qPCR), and MTT assays, CCK-8 assays, Transwell assays, wound healing assays and flow cytometry were performed to investigate the function of miR-136-5p in RCC. RT-qPCR revealed that the expression of miR-136 was significantly lower in RCC tissues and cells compared with adjacent non-tumor tissues and cells in vitro. miR-136-5pwas also demonstrated to be associated with RCC cell proliferation, viability, migration, invasion and apoptosis. miR-136-5p may therefore function as a tumor suppressor in RCC. Further studies are required to elucidate the molecular mechanisms and signaling pathways underlying these functions of miR-136-5p, to investigate the potential function of miR-136-5p as a biomarker for the early detection
\end{abstract}

Correspondence to: Professor Yongqing Lai, Department of Urology, Peking University Shenzhen Hospital, 1120 Lianhua Road, Shenzhen, Guangdong 518036, P.R. China

E-mail: yqlord@163.com

Professor Tao Wang, Department of Cardiovascular Surgery, Peking University Shenzhen Hospital, 1120 Lianhua Road, Shenzhen, Guangdong 518036, P.R. China

E-mail: szwangtao@126.com

*Contributed equally

Key words: microRNA-136-5p, renal cell carcinoma, suppressor and prognosis of $\mathrm{RCC}$, and its potential as a therapeutic target for the treatment of RCC.

\section{Introduction}

Renal cell carcinoma (RCC) is the third most common urological neoplasm following prostate and bladder cancer, and accounts for $2 \%$ of all cancer-associated mortality in the United States of America (1). The disease is comprised of $>10$ histological and molecular subtypes, of which clear cell RCC (ccRCC) is the most common, accounting for $\sim 70 \%$ of all diagnosed cases $(1,2)$. Prognosis is closely associated with the stage of RCC at the point of diagnosis. The 5-year survival rate of stage I RCC is $\sim 95 \%$, while that of stage IV is just $20 \%$ (2). Therefore, early detection of RCC is of great importance for successful treatment. However, during early stage RCC there are typically no clear symptoms, making diagnosis difficult, and $\sim 25-30 \%$ of patients with RCC are metastatic at diagnosis (3). At present, no standardized approaches to biomarker sampling or analysis have been adopted for RCC since the majority of the putative tumor markers themselves remain under active investigation for further validation (4). Reliable biomarkers have not yet been established for screening (2). In addition, there are no data suggesting that adjuvant therapies such as cytokines and vaccines were effective following RCC surgery (5).

MicroRNAs (miRNAs/miRs) are short, non-coding single stranded RNAs with 20-22 nucleotides that regulate the expression of their target genes at the post-transcriptional level (6). An increasing body of evidence implicates miRNAs in various aspects of tumorigenesis (1). In addition, certain miRNAs are considered to be potential cancer biomarkers and anti-cancer therapeutics (7). Previous studies have demonstrated that several miRNAs are dysregulated in RCC, and result in aberrant cell growth, angiogenesis, apoptosis and autophagy (6,8-10).

Previous studies have demonstrated that miR-136-5p is involved in a number of types of carcinoma, including 
glioma (11), triple-negative breast cancer (12) and non-small cell lung cancer (NSCLC) (13). However, the function of miR-136-5p in RCC remains to be explored. In the present study, miR-136-5p was revealed to function as a tumor suppressor in RCC, as it repressed migration, invasion, viability, proliferation and promoted apoptosis in in vitro experiments.

\section{Materials and methods}

Sample collection. A total of 28 tumor samples and matched non-tumor kidney tissues were obtained from Peking University Shenzhen Hospital (Shenzhen, China) between January 2015 and January 2016. The normal kidney tissue was obtained by sampling $2 \mathrm{~cm}$ away from the tumor tissue. The specimens were frozen in liquid nitrogen $\left(-195.8^{\circ} \mathrm{C}\right)$ until RNA extraction. The present study was approved by the local Ethics Committee of Peking University Shenzhen Hospital (Shenzhen, China), and written informed consent was obtained from all patients. The clinic pathological features of all patients are listed in Table I.

$R N A$ extraction and reverse-transcription quantitative polymerase chain reaction $(R T-q P C R)$. Total RNA was extracted from the RCC tissue and adjacent tissue using TRIzol reagent (Invitrogen; Thermo Fisher Scientific, Inc., Waltham, MA, USA) and was purified using the RNeasy Maxi kit (Qiagen $\mathrm{GmbH}$, Hilden, Germany) following the manufacturer's protocols. The concentration of the RNA was measured using a NanoDrop 2000/2000c spectrophotometer (NanoDrop Technologies; Thermo Fisher Scientific, Inc., Pittsburgh, PA, USA). The miScript Reverse Transcription kit (Qiagen GmbH) was used to prepare cDNA from $1 \mu \mathrm{g}$ RNA. The reverse transcription process consisted of $37^{\circ} \mathrm{C}$ for $60 \mathrm{~min}, 95^{\circ} \mathrm{C}$ for $5 \mathrm{~min}$ and then storage at $4^{\circ} \mathrm{C}$. To analyze the expression of miR-136-5p, qPCR was conducted using the resultant cDNA with the miScript SYBR ${ }^{\circledR}$ Green PCR kit (Qiagen GmbH) following the manufacturer's protocol, on the Roche Light Cycler 480 Real-Time PCR System (Roche Diagnostics, Basel, Switzerland). The thermocycler conditions were as follows: $95^{\circ} \mathrm{C}$ for $1 \mathrm{~min}, 40$ cycles of $95^{\circ} \mathrm{C}$ for $15 \mathrm{sec}, 55^{\circ} \mathrm{C}$ for $30 \mathrm{sec}$ and $72^{\circ} \mathrm{C}$ for $30 \mathrm{sec}$. The sequences of the primers for miR-136-5p and the internal control, U6, are presented in Table II. The $2^{-\Delta \Delta \mathrm{Cq}}$ method was used to analyze the expression of miR-136-5p (14).

Cell culture and transfection. A normal human embryo kidney cell line (293T) and two RCC cell lines (786-O and ACHN) were obtained from the Guangdong and Shenzhen Key Laboratory of Male Reproductive Medicine and Genetics (Shenzhen, China). Cells were cultured in Dulbecco's modified Eagle's medium (DMEM; Gibco; Thermo Fisher Scientific, Inc.) supplemented with $10 \%$ fetal bovine serum (FBS; Gibco; Thermo Fisher Scientific, Inc.), $1 \%$ penicillin-streptomycin (Gibco; Thermo Fisher Scientific, Inc.) and 1\% glutamine (Gibco; Thermo Fisher Scientific, Inc.) at $37^{\circ} \mathrm{C}$ in a $5 \% \mathrm{CO}_{2}$ humidified incubator. Transfection was performed with miR-136-5p mimics, miR-136-5p inhibitors, negative control (NC) miRNA and inhibitor negative control (inhibitor NC) miRNA (5 pmol; Shanghai GenePharma Co., Ltd., Shanghai,
China) using Lipofectamine 2000 reagent (Invitrogen; Thermo Fisher Scientific, Inc.) according to the manufacturer's protocol when cells were at $70 \%$ confluence. The sequences of mimics, inhibitor, $\mathrm{NC}$ and inhibitor $\mathrm{NC}$ are presented in Table II. Following transfection, RT-qPCR was used to assess transfection efficiency and the expression of miR-136-5p.

Cell Counting Kit-8 (CCK-8) assay. Cells $\left(5 \times 10^{3}\right)$ transfected with 5 pmol miR-136-5p mimics, inhibitors, $\mathrm{NC}$ or inhibitor $\mathrm{NC}$ were seeded in 96-well plates and then incubated at $37^{\circ} \mathrm{C}$. After 0, 24, 48 and $72 \mathrm{~h}, 10 \mu \mathrm{lCCK}-8$ reagent (Beyotime Institute of Biotechnology, Haimen, China) was added into each well of a 96 -well plate for $30 \mathrm{~min}$ at $37^{\circ} \mathrm{C}$, and then the absorbance values of the experimental wells were read at $490 \mathrm{~nm}$.

MTT assay. Following transfection with 5 pmol miR-136-5p mimics, NC, miR-136-5p inhibitors or inhibitor $\mathrm{NC}, \sim 5 \times 10^{3}$ cells were seeded into each well of a 96 -well plate and incubated for 4 days. Following addition of $20 \mu \mathrm{l} \mathrm{MTT}(5 \mathrm{mg} / \mathrm{ml}$; Sigma-Aldrich; Merck KGaA, Darmstadt, Germany) to the plate, the cells were incubated for a further $4 \mathrm{~h}$ at $37^{\circ} \mathrm{C}$. The medium was discarded, $100 \mu 1$ DMSO was added into each well, and the plates were shaken on a reciprocating decolorization shaking table (TSB-108 Qilinbeier, Jiangsu, China; http://www.qilinbeier.cn/tsb-108.html) for $10 \mathrm{~min}$ in the dark. Then, the absorbance values were read at $595 \mathrm{~nm}$ using an ELISA microplate reader (680; Bio-Rad Laboratories, Inc., Hercules, CA, USA).

Wound healing assay. Cells $\left(5 \times 10^{5}\right)$ were seeded into each well of a 12-well plate, and incubated until they formed a monolayer of $\sim 80 \%$ confluent cells. Cells were then transfected with 100 pmol chemically synthesized miRNA-136-5p inhibitors, mimics, NC or inhibitor NC, as aforementioned. A wound was created with a sterile $200 \mu$ l pipette tip, and floating cells were washed away using phosphate-buffered saline (PBS). Cell images were taken at 0 and $12 \mathrm{~h}$ after making the scratch using a digital camera system, and the temperature of incubation subsequent to making the scratch was $37^{\circ} \mathrm{C}$.

Transwell assay. Transwell chamber inserts (BD Biosciences, Franklin Lakes, NJ, USA) with or without Matrigel (for invasion assays) were used. Serum-free medium (200 $\mu$ l DMEM) containing $\sim 1 \times 10^{4}$ transfected cells was seeded into upper chamber of the insert. Medium mixed with $10 \%$ FBS was added to the lower chamber of the inserts. 786-O cells and ACHN cells were incubated at $37^{\circ} \mathrm{C}$ for $36 \mathrm{~h}$ for the migration assay, and were incubated for 48 and $60 \mathrm{~h}$, respectively, for the invasion assay. All non-migrated cells were removed by a cotton swab. The cells that had migrated or invaded to the other side of the membrane were stained with $0.1 \%$ crystal violet for $25 \mathrm{~min}$ at $25^{\circ} \mathrm{C}$ and counted for in three fields of view using a microscope (Leica DMIRB Inverted Fluorescence Microscope, Leica Microsystems GmbH, Wetzlar, Germany).

Flow cytometry assay. Cells were seeded in a 6-well plate ( $3 \times 10^{5}$ cells/well) and maintained in a humidified incubator with $5 \% \mathrm{CO}^{2}$ at $37^{\circ} \mathrm{C}$ until they formed an $\sim 80 \%$ confluent monolayer. Cells were then transfected with 200 pmol 
Table I. Clinicopathological features of patients with renal cell carcinoma.

\begin{tabular}{lc}
\hline Characteristic & No. of patients \\
\hline Mean age, range (years) & $45(25-62)$ \\
Sex & \\
Male & 9 \\
Female & 19 \\
Histological type & \\
Clear cell & 24 \\
Papillary & 4 \\
pT-stage & \\
T1 & 19 \\
T2 & 7 \\
T3+4 & 2 \\
Fuhrmann grade & \\
I & 7 \\
II & 18 \\
III & 2 \\
IV & 1 \\
AJCC clinical stage & \\
I & 8 \\
II & 18 \\
III + IV & 2 \\
\hline
\end{tabular}

pT, primary tumor; AJCC, American Joint Committee on Cancer.

miR-136-5p mimics, inhibitors, NC or inhibitor NC. Following transfection for $48 \mathrm{~h}$, cells were gathered and washed twice with cold PBS. Then, the cells were re-suspended in $100 \mu \mathrm{l}$ $1 \mathrm{X}$ binding buffer (Alexa Fluor 488 Annexin V/Dead Cell Apoptosis kit, Invitrogen; Thermo Fisher Scientific, Inc.) to create a single-cell suspension. Cell suspension $(50 \mu \mathrm{l}), 5 \mu \mathrm{l}$ Annexin V-fluorescein isothiocyanate and $5 \mu \mathrm{l}$ propidium iodide (Alexa Fluor 488 Annexin V/Dead Cell Apoptosis kit) were mixed and then incubated in room temperature for $15 \mathrm{~min}$ in the dark Following the addition of $400 \mu \mathrm{l}$ binding buffer, the samples were analyzed using a flow cytometer (EPICS, Xl-4; Beckman Coulter, Inc., Brea, CA, USA), and the software used for data analysis was FlowJo v 10 (TreeStar, Inc., Ashland, OR, USA).

Bioinformatics analysis. Potential targets of miR-136-5p were predicted through the combination of four public algorithms, including miRWalk (15) (www.umm.uni-heidelberg. de/apps/zmf/mirwalk), miRanda (16) (www.microrna.org), PicTar (pictar.mdc-berlin.de) and TargetScan (17) (www .targetscan.org). All four algorithms accepted the predicted genes, which were selected based on gene function.

Statistical analysis. Each experiment was performed in triplicate and repeated at least three times. The data are presented as the mean \pm standard deviation. MiR-136 expression levels between groups were analyzed using paired Student's t-tests, with the exception of relative expression of miR-136-5p in
Table II. Sequences of primers and miRs.

\begin{tabular}{|c|c|}
\hline Primer & Sequence $\left(5^{\prime}-3^{\prime}\right)$ \\
\hline \multicolumn{2}{|l|}{$\operatorname{miR}-136-5 p$} \\
\hline Forward & ACTCCATTTGTTTTGATGATGGA \\
\hline Reverse & $\begin{array}{l}\text { Reverse provided by the miScript } \mathrm{SYBR}{ }^{8} \\
\text { Green kit }\end{array}$ \\
\hline \multicolumn{2}{|l|}{ U6 } \\
\hline Forward & CTCGCTTCGGCAGCACA \\
\hline Reverse & ACGCTTCACGAATTTGCGT \\
\hline \multicolumn{2}{|l|}{$\begin{array}{l}\operatorname{miR}-136-5 p \\
\text { mimics }\end{array}$} \\
\hline Forward & ACUCCAUUUGUUUUGAUGAUGGA \\
\hline Reverse & CAUCAUCAAAACAAAUGGAGUUU \\
\hline \multicolumn{2}{|l|}{$\mathrm{NC}$} \\
\hline Forward & UUCUCCGAACGUGUCACGUTT \\
\hline Reverse & ACGUGACACGUUCGGAGAATT \\
\hline $\begin{array}{l}\operatorname{miR}-136-5 p \\
\text { inhibitor }\end{array}$ & UCCAUCAUCAAAACAAAUGGAGU \\
\hline NC inhibitor & CAGUACUUUUGUGUAGUACAA \\
\hline
\end{tabular}

cells as presented in Fig. 1, which was analyzed using one-way analysis of variance followed by Dunnett's post hoc test. A paired Student's t-test was also used to analyze the results of assays to characterize cell phenotype. All statistical calculations were performed using SPSS 19.0 software (IBM Corp., Armonk, NY, USA). $\mathrm{P}<0.05$ was considered to indicate a statistically significant difference.

\section{Results}

miR-136-5p is downregulated in RCC tissues and cell lines. RT-qPCR was performed to examine the expression levels of miR-136-5p in 28 paired RCC tissues and cell lines. As presented in Fig. 1A, the ratio of miR-136-5p expression [ $\log _{2}$ Ratio $\left.(\mathrm{T} / \mathrm{N})\right]$ was revealed to be downregulated in the RCC tissues from 22/28 patients. Mean expression levels are presented in Fig. 1B, and revealed that the expression of miR-136-5p in RCC tissues was significantly decreased compared with adjacent normal tissues $(\mathrm{P}<0.01)$. Furthermore, miR-136-5p expression levels were significantly decreased in ACHN $(\mathrm{P}<0.05)$ and 786-O $(\mathrm{P}<0.05) \mathrm{RCC}$ cell lines compared with the 293T normal kidney human embryo kidney cell line, as presented in Fig. 1C.

Validation of cell transfection efficiency. qPCR was performed to assess the transfection efficiency of miR-136-5p mimics or $\mathrm{NC}$ and miR-136-5p inhibitors or inhibitor NC. Compared with the NC group, the expression levels of miR-136-5p were 145.00 times higher in ACHN cells $(\mathrm{P}<0.01)$ and 67.33 times higher in 786-O cells $(\mathrm{P}<0.001)$ transfected with miR-136-5p. Compared with the inhibitor NC group, miR-136-5p expression levels were 0.16 times that in ACHN cells $(\mathrm{P}<0.01)$ and 0.09 times that in $786-\mathrm{O}$ cells $(\mathrm{P}<0.001)$ following transfection with miR-136-5p inhibitors (Fig. 1D). 

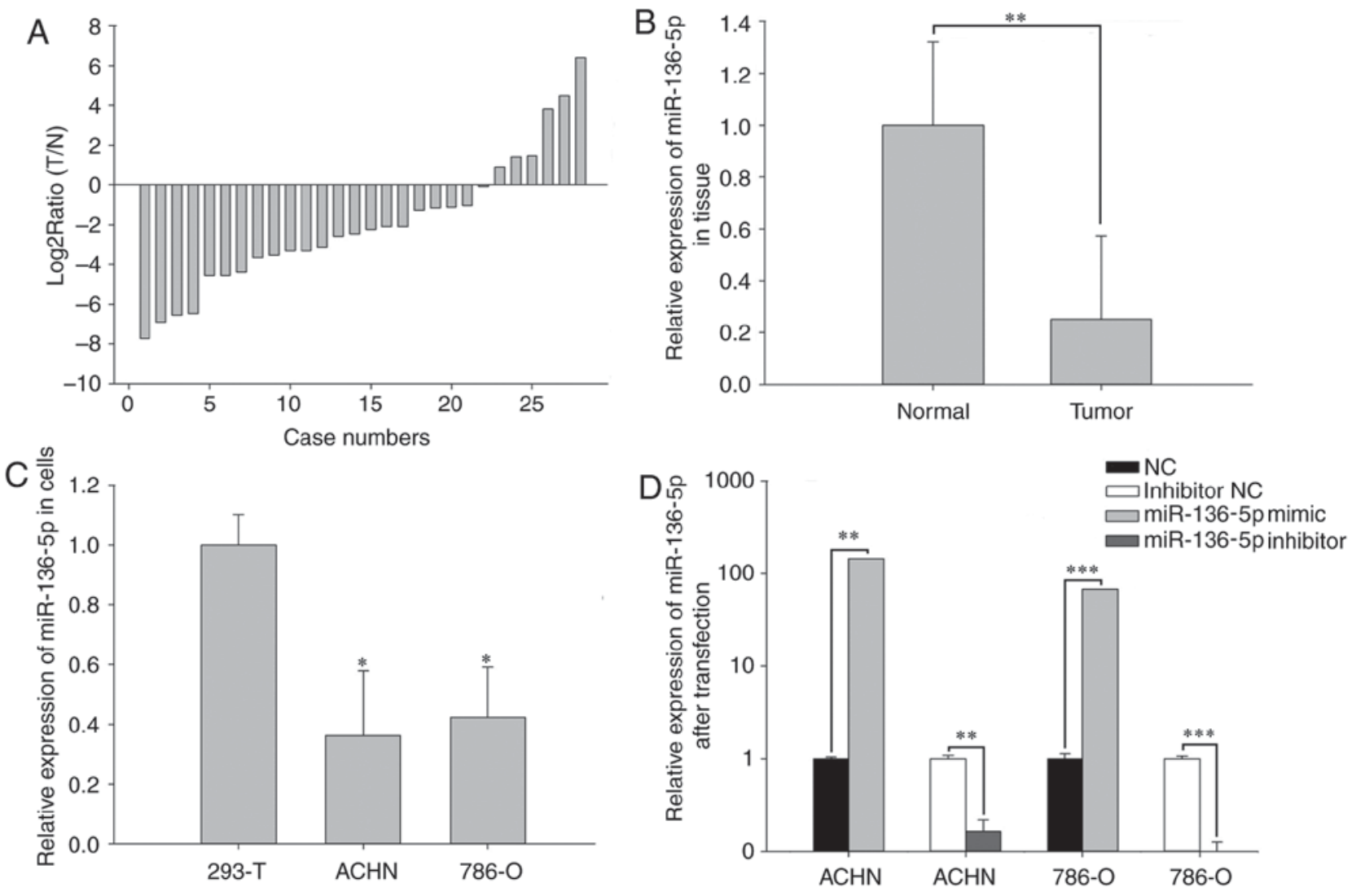

Figure 1. (A) $\log _{2}$ ratios (T/N) of miR-136-5p in 28 paired renal cell carcinoma tissues. (B) Relative expression levels of miR-136-5p in RCC and normal tissues. (C) Relative expression levels of miR-136-5p in 293T, ACHN and 786-O cell lines. (D) Relative expression levels of miR-136-5p in RCC cell lines following transfection. ${ }^{*} \mathrm{P}<0.05,{ }^{* *} \mathrm{P}<0.01$ and ${ }^{* * * *} \mathrm{P}<0.001$, vs. the respective controls. miR, microRNA; NC, negative control; T, renal cell carcinoma tissues; $\mathrm{N}$, normal tissues.

Upregulation of miR-136-5p inhibits RCC cell proliferation and downregulation of miR-136-5p promotes $R C C$ cell proliferation. The effect of miR-136-5pon proliferation was determined using a CCK-8 assay (Fig. 2). Following transfection with miR-136-5p mimics, the proliferation of ACHN cells was decreased by $13.97 \%$ ( $24 \mathrm{~h} ; \mathrm{P}<0.01), 28.15 \%(48 \mathrm{~h} ; \mathrm{P}<0.01)$ and $19.21 \%$ ( $72 \mathrm{~h} ; \mathrm{P}<0.01)$, while that of $786-\mathrm{O}$ cells was decreased by $6.67 \%(24 \mathrm{~h}), 14.35 \%(48 \mathrm{~h} ; \mathrm{P}<0.05)$ and $17.62 \%$ (72 h; $\mathrm{P}<0.001)$, respectively, compared with the NC group (Fig. 2A and C). Furthermore, following transfection with miR-136-5p inhibitors, the proliferation of ACHN cells was increased by $10.15 \%$ ( $24 \mathrm{~h} ; \mathrm{P}<0.05), 28.30 \%$ ( $48 \mathrm{~h} ; \mathrm{P}<0.01)$ and $40.19 \%$ ( $72 \mathrm{~h} ; \mathrm{P}<0.01)$, while that of $786-\mathrm{O}$ cells was increased by $8.29 \%(24 \mathrm{~h} ; \mathrm{P}<0.05), 11.97 \%(48 \mathrm{~h} ; \mathrm{P}<0.05)$ and $20.45 \%$ (72 h; $\mathrm{P}<0.001$ ), respectively, compared with the inhibitor NC group (Fig. 2B and D).

Upregulation of miR-136-5p inhibits RCC cell viability and downregulation of miR-136 promotes $R C C$ cell viability. The effect of miR-136-5p on cell viability was determined using an MTT assay. As presented in Fig. 2E, the viability of ACHN cells transfected with the miR-136-5p mimic was reduced by $12.89 \%(\mathrm{P}<0.01)$ compared with the NC group, while the viability of cells transfected with the miR-136-5p inhibitor was increased by $16.39 \%(\mathrm{P}<0.01)$ compared with the inhibitor NC group. Similarly, the viability of $786-O$ cells transfected with the miR-136-5p mimic was decreased by $16.71 \%(\mathrm{P}<0.05)$ compared with the NC group, while the viability of cells transfected with the miR-136-5p inhibitor was increased by $13.15 \%$ $(\mathrm{P}<0.05)$ compared with the inhibitor NC group (Fig. 2F).

Upregulation of miR-136-5p inhibits RCC cell migration and invasion, while downregulation of miR-136-5p promotes $R C C$ cell migration and invasion. The effect of miR-136-5p on RCC cell mobility was determined using wound healing assays and Transwell assays (Figs. 3 and 4). Representative images of the wound healing assay are presented in Fig. 3A. The wound healing assay revealed that, compared with the $\mathrm{NC}$ group, the migration of the mimic group was reduced by $28.53 \%(\mathrm{P}<0.05$; Fig. 3C) in ACHN cells and by $27.99 \%$ ( $\mathrm{P}<0.05$; Fig. 3B) in 786-O cells $12 \mathrm{~h}$ following the initial scratch. In contrast, compared with the inhibitor $\mathrm{NC}$ group, the migration of the inhibitor group was increased by $73.14 \%(\mathrm{P}<0.01$; Fig. $3 \mathrm{C})$ in ACHN cells and by $31.08 \%(\mathrm{P}<0.05$; Fig. $3 \mathrm{~B})$ in $786-\mathrm{O}$ cells $12 \mathrm{~h}$ following the initial scratch.

As presented in Fig. 4C, the Transwell assay revealed that, following transfection with miR-136-5p mimics, ACHN cell migration was reduced by $60.34 \%$ compared with the NC group $(\mathrm{P}<0.01)$, while the cells transfected with miR-136-5p inhibitors was increased by $100.26 \%$ compared with the inhibitor $\mathrm{NC}$ group $(\mathrm{P}<0.01)$. The invasion of ACHN cells transfected with miR-136-5p mimics was reduced by $75.52 \%$ compared with the $\mathrm{NC}$ group $(\mathrm{P}<0.01)$, while the invasion of cells transfected with miR-136-5p inhibitors was increased 


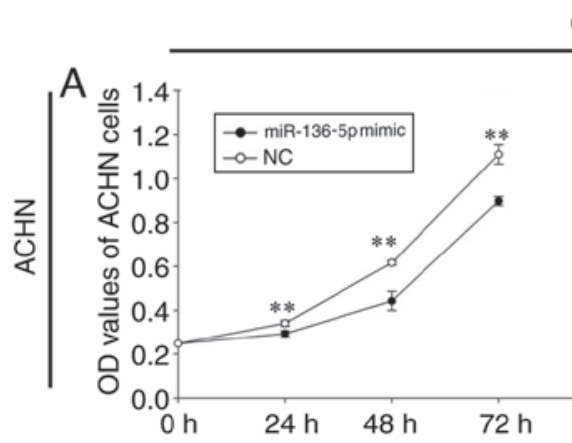

CCK-8 assay
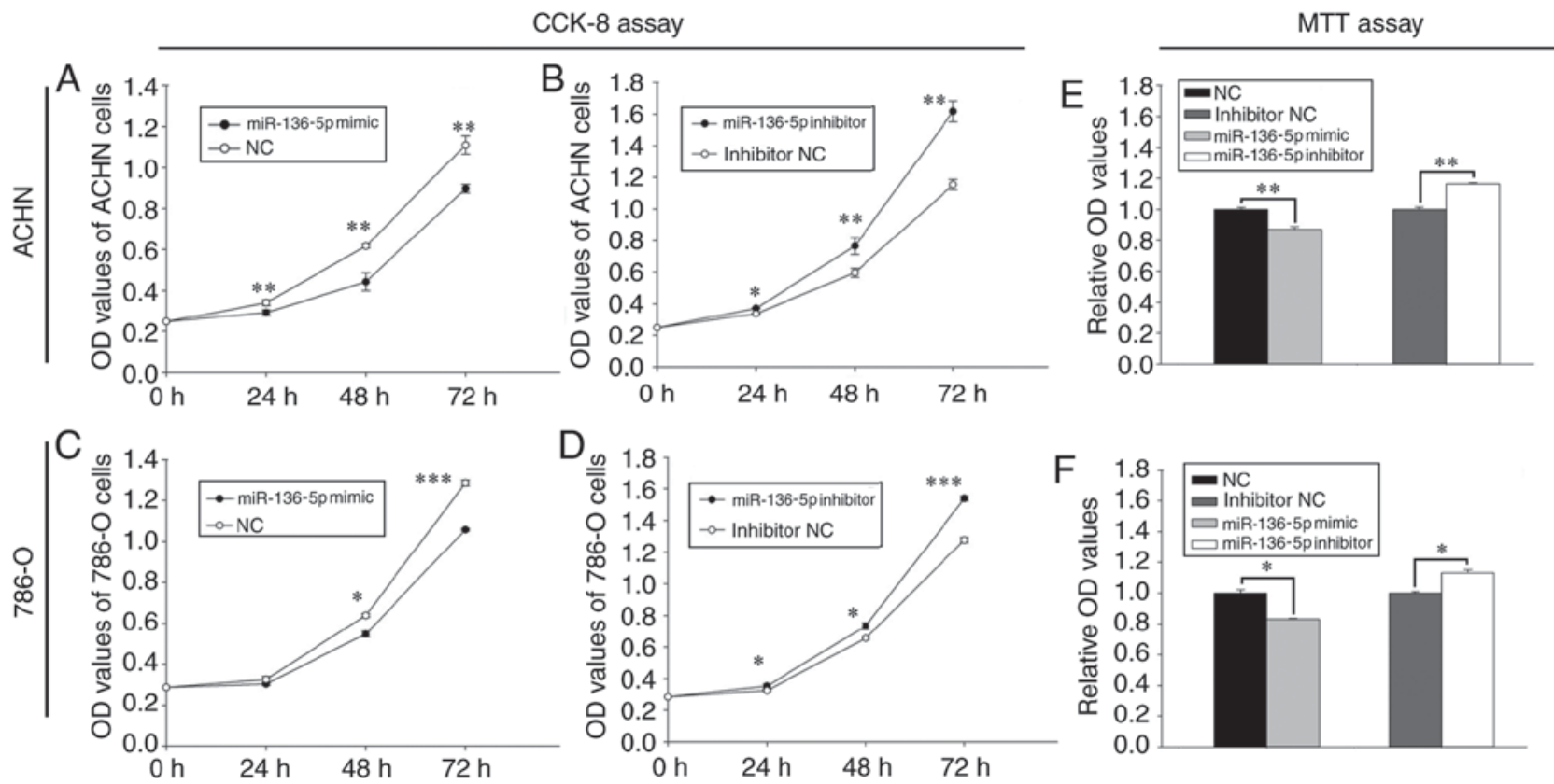

Figure 2. Analysis of cell proliferation and viability with CCK-8 and MTT assays. ACHN cells were transfected with (A) miR-136-5p mimics and NC and (B) miR-136-5p inhibitors and inhibitor NC, and proliferation was assessed using a CCK-8 assay. 786-O cells were transfected with (C) miR-136-5p mimics and $\mathrm{NC}$ and (D) miR-136-5p inhibitors and inhibitor NC, and proliferation was assessed using a CCK-8 assay. Cell viability was analyzed in (E) ACHN and (F) 786-O cells using an MTT assay. ${ }^{*} \mathrm{P}<0.05,{ }^{* *} \mathrm{P}<0.01$ and ${ }^{* * * *} \mathrm{P}<0.001$ vs. the respective controls. CCK-8, Cell Counting Kit 8 ; miR, microRNA; NC, negative control; OD, optical density.
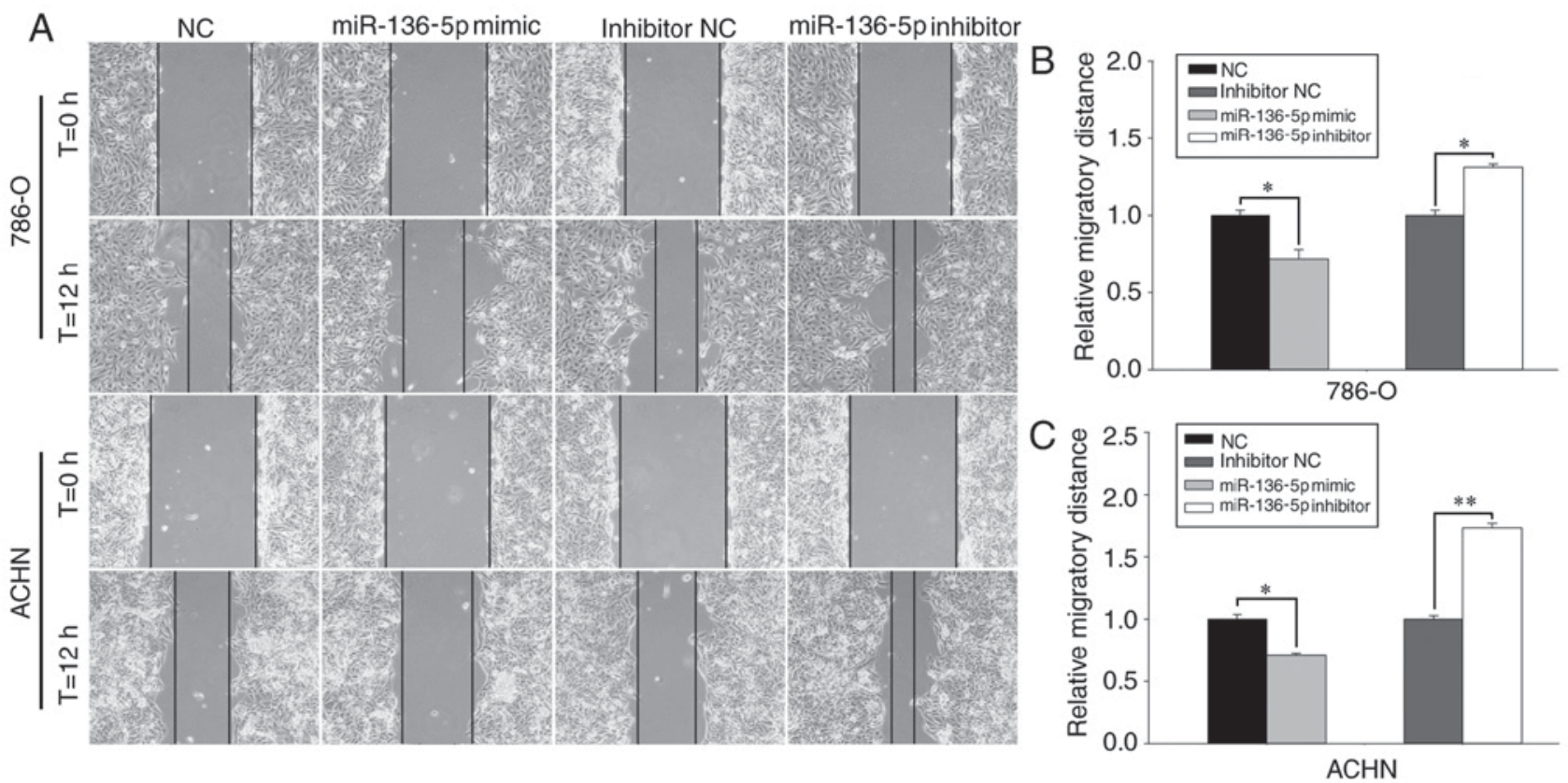

Figure 3. Analysis of migration using wound healing assays. (A) Representative migratory images (magnification, x100). Migratory distances in (B) 786-O cells and (C) ACHN cells following transfection. ${ }^{*} \mathrm{P}<0.05$ and ${ }^{* *} \mathrm{P}<0.01$, with comparisons indicated by lines. miR, microRNA; NC, negative control.

by $109.52 \%$ compared with the inhibitor $\mathrm{NC}$ group $(\mathrm{P}<0.05$; Fig. 4C). Similarly, the migration of 786-O cells transfected with miR-136-5p mimics was reduced by $49.02 \%$ compared with the $\mathrm{NC}$ group $(\mathrm{P}<0.01)$, while the migration of cells transfected with miR-136-5p inhibitor was increased by $84.09 \%$ compared with the inhibitor NC group $(\mathrm{P}<0.05$; Fig. 4B). The invasion of 786-O cells transfected with miR-136-5p mimics was reduced by $78.41 \%$ compared with the $\mathrm{NC}$ group $(\mathrm{P}<0.01)$, while the cells transfected with miR-136-5p inhibitors was promoted by $60.63 \%$ compared with the inhibitor NC group ( $\mathrm{P}<0.01$; Fig. 4B).

Upregulation of miR-136-5p induces apoptosis and downregulation of miR-136-5p suppresses cell apoptosis. Flow cytometry was used to assess the effect of miR-136-5p on apoptosis (Fig. 5A). The results revealed that the early 

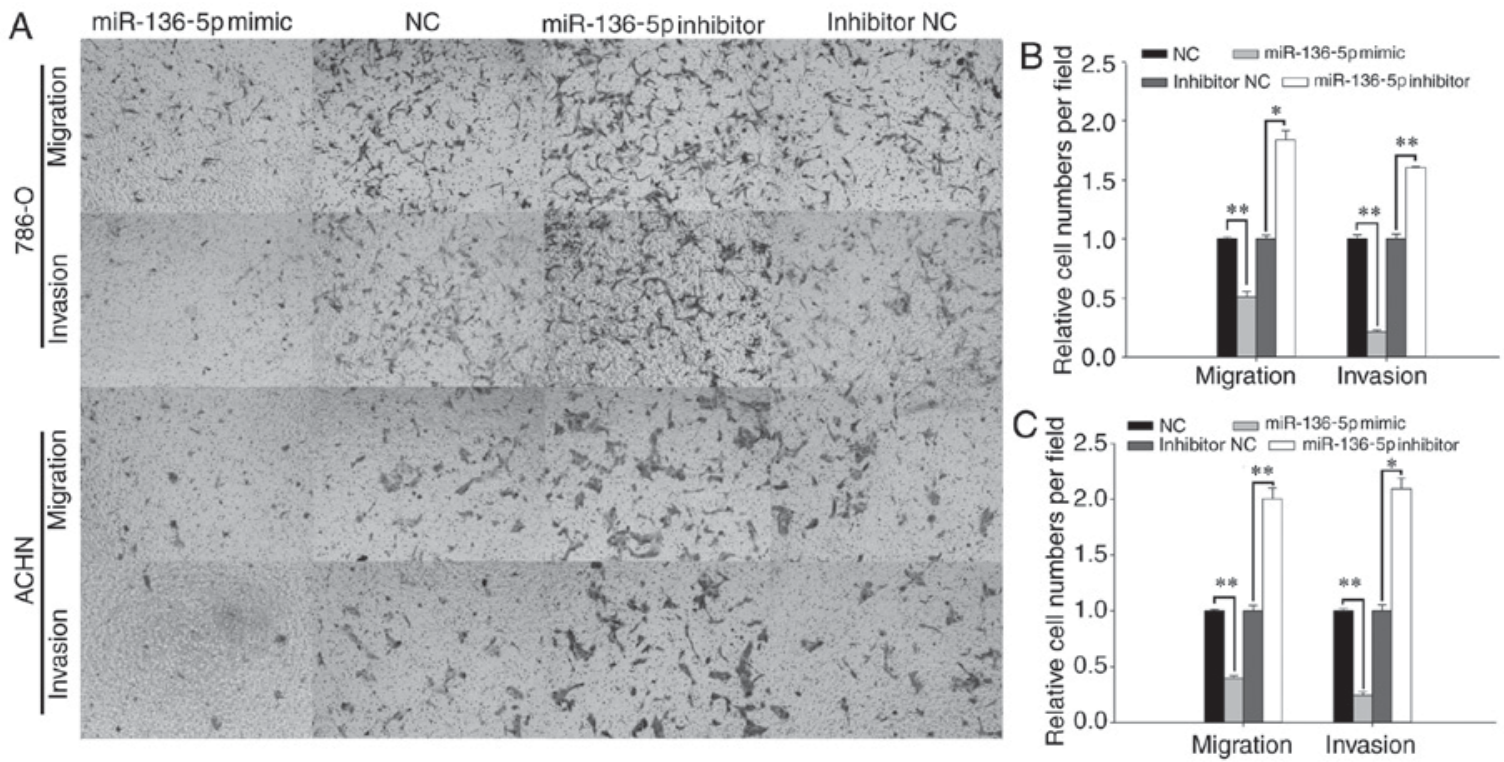

Figure 4. Migration and invasion were assessed using Transwell assays. (A) Representative images (magnification, $\mathrm{x} 100$ ) of migrating and invading 786-O and ACHN cells, with quantification in (B) 786-O cells and (C) ACHN cells. ${ }^{*} \mathrm{P}<0.05$ and ${ }^{* *} \mathrm{P}<0.01$, with comparisons indicated by lines. miR, microRNA; NC, negative control.

apoptosis rate of 786-O cells transfected with miR-136-5p mimics and $\mathrm{NC}$ was $27.56 \pm 0.40$ and $16.73 \pm 0.26 \%$, respectively $(\mathrm{P}<0.01$; Fig. 5B), while the early apoptosis rate of $786-\mathrm{O}$ cells transfected with miR-136-5p inhibitors and inhibitor NC was $12.93 \pm 0.34$ and $17.66 \pm 0.32 \%$, respectively $(\mathrm{P}<0.05$; Fig. $5 \mathrm{~B})$. Similarly, the early apoptosis rate of ACHN cells transfected with miR-136-5p mimics and $\mathrm{NC}$ was $31.4 \pm 0.78$ and $24.26 \pm 0.66 \%$, respectively $(\mathrm{P}<0.05$; Fig. $5 \mathrm{C})$, while the early apoptosis rate of ACHN cells transfected with miR-136-5p inhibitors and inhibitor NC was $15.03 \pm 0.93$ and $24.33 \pm 0.72 \%$, respectively $(\mathrm{P}<0.05$; Fig. $5 \mathrm{C})$.

Target gene prediction. Four algorithms were combined to predict the putative target genes of miR-136-5p. All four algorithms simultaneously predicted that dedicator of cytokinesis 5 (DOCK5) was a potential target. The complementary site for the seed sequences of miR-136-5p was 5'-AAUGGAGA-3' in the DOCK5 3'-untranslated region.

\section{Discussion}

MiRNAs may be critical in the development, proliferation, communication and death of cells, as well as in tissue differentiation (18). Emerging evidence suggests that miRNAs are involved in tumor development and progression (19). In the present study, miR-136-5p was revealed to be downregulated in RCC tissues and cell lines compared with adjacent non-tumor tissues and cells in vitro. Furthermore, cell proliferation, migration and invasion were demonstrated to be suppressed following upregulation of miR-136-5p. Apoptosis was also induced by upregulation of miR-136-5p.

Previous studies have provided evidence that miR-136-5p serves either an oncogenic or a tumor-suppressing function in the development of carcinomas. For example, in NSCLC, expression of miR-136-5p promoted cell proliferation by promoting extracellular signal-regulated kinase (ERK)1/2 phosphorylation via the targeting of protein phosphatase 2 regulatory subunit $\mathrm{B} \alpha$ (PPP2R2A) (13). This result supports the hypothesis that miR-136 acts as an oncogene in NSCLC.

In contrast, Jeong et al (11) demonstrated that miR-136-5p targeted the Notch 3 oncogene and functions as an ovarian cancer suppressor (11). miR-136-5p was also reported to be downregulated in triple-negative breast cancer by targeting RAS protein activator like 2, and act as a tumor suppressor (12). Yang et al (20) also described miR-136-5p as a tumor suppressor in lung adenocarcinoma, and revealed that this occurred through the targeting of SMAD family member (Smad)2 and Smad3. In a previous study, miR-136-5p was revealed to be downregulated in metastatic giant cell bone tumors compared to non-metastatic giant cell bone tumors, by promoting nuclear factor I B expression (21). In another study concerning glioma, miR-136-5p was revealed to serve a tumor-suppressive function in human glioma by upregulating the expression of astrocyte elevated gene-1 and B cell lymphoma-2 (BCL2) (22). In another study, overexpression of miR-136-5p negatively impacted proliferation of the LN229 glioblastoma cell line by downregulating matricellular cysteine rich angiogenic inducer 61 protein expression (23). miR-136-5p was also reported to be serve as an anti-oncogene in epithelial ovarian cancer (24). Gao et al (25) demonstrated that colorectal neoplasia differentially expressed is a target of miR-136-5p in colorectal cancer cells, and high levels of miR-136-5p may inhibit the migration and invasion of colorectal cancer cells. Consistent with these results, the present study demonstrated that transfection with miR-136-5p mimics inhibited proliferation, invasion, and migration and induced apoptosis in the 780-O and ACHN cell lines, supporting the hypothesis that miR-136-5p is a tumor-suppressor in RCC. Together, these data indicate that the biological function of miR-136 is involved in the tumorigenesis and progression of various types of human cancer.

In addition, miRNAs may be used as biomarkers to improve our knowledge on diagnosis, prognosis and drug resistance, 

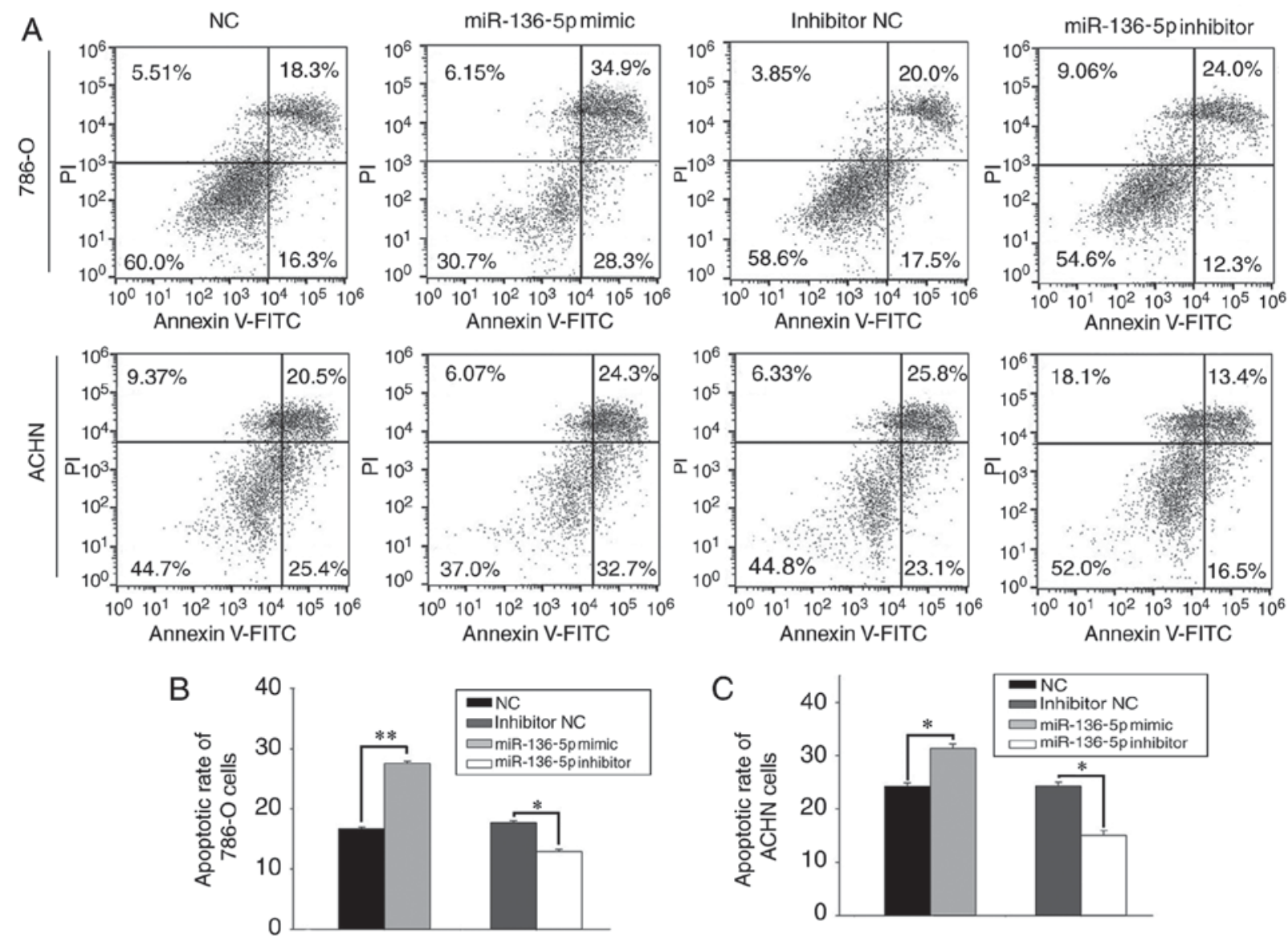

Figure 5. Apoptosis was analyzed with flow cytometry. (A) Representative flow cytometry results in 786-O and ACHN cells, with quantification in (B) 786-O cells and (C) ACHN cells. ${ }^{*} \mathrm{P}<0.05$ and ${ }^{* *} \mathrm{P}<0.01$, with comparisons indicated by lines. miR, microRNA; PI, propidium iodide; FITC, fluorescein isothiocyanate; $\mathrm{NC}$, negative control.

and may be used as therapeutic approaches in certain types of cancer. For example, miR-136-5p may be a potential biomarker for ccRCC (26). Overexpression of miR-136-5p may be associated with poor prognosis in giant cell bone tumors (18). $\mathrm{Wu}$ et al (27) reported that miR-136-5p functions as a predictor of the response to temozolomide therapy, and serves as a novel potential maker for glioma therapy. Chen et al (28) demonstrated that miR-136-5p was associated with cisplatin resistance and functions as a tumor suppressor in glioma. miR-136-5p has also been reported to inhibit cancer stem cell activity and increase the anti-tumor effect of paclitaxel on ovarian cancer chemotherapy tolerance (11). Zhao et al (29) reported that miR-136-5p may have therapeutic potential in hepatitis B virus-associated hepatocellular carcinoma. Therefore, miR-136-5p has the potential to be a diagnostic or a prognostic biomarker for RCC, and this should be confirmed by further research.

In addition to being associated with tumors, miR-136-5p is also associated with multiple non-neoplastic diseases. Ji et al (30) demonstrated that high level of miR-136-5p suppressed cell proliferation and promoted apoptosis of mesenchymal stem cells through targeting BCL2, which is a potential causal factor of preeclampsia. Zhang et al (31) demonstrated that miR-136-5p is involved in keratinocyte growth through targeting PPP2R2A, and may be a novel treatment target for the improvement of skin wound healing (31). Aberrant miR-136-5p upregulation in atherosclerosis contributes to abnormal vascular smooth muscle cell proliferation via the ERK1/2 signaling pathway by targeting PPP2R2A (32).

The mechanism underlying the effect of miR-136-5p in $\mathrm{RCC}$ requires further exploration, and improved understanding of the cellular function of ectopic miRNAs provides novel insights into RCC (33). In the present study, miR-136-5p was demonstrated to functions as a tumor suppressor in RCC, and may consequently serve as a therapeutic target for RCC.

In conclusion, the present study demonstrated that miR-136-5p served as a tumor suppressor, inhibited growth, viability, migration, invasion and induced apoptosis of RCC cells. Therefore, it may be associated with the development and progression of RCC. In addition, these results underscore the clinical potential of miR-136-5p in RCC treatment, and support the development of effective therapeutic strategies that target miR-136-5p.

\section{Acknowledgements}

The present study was supported by the National Natural Science Foundation of China (grant no. 81101922), the Science and Technology Development Fund Project of Shenzhen (grant nos. JCYJ20150403091443329 and JCYJ20170307111334308), the San-ming Project of Medicine in Shenzhen (grant no. SZSM201612066) and the Guangdong Key Medical Subject Fund. 


\section{Competing interests}

The authors declare that they have no competing interests.

\section{References}

1. Wang Z, Qin C, Zhang J, Han Z, Tao J, Cao Q, Zhou W, Xu Z, Zhao $\mathrm{C}$, Tan $\mathrm{R}$ and $\mathrm{Gu} \mathrm{M}$ : MiR-122 promotes renal cancer cell proliferation by targeting Sprouty 2. Tumour Biol 39: 1010428317691184,2017

2. Hsieh JJ, Purdue MP, Signoretti S, Swanton C, Albiges L, Schmidinger M, Heng DY, Larkin J and Ficarra V: Renal cell carcinoma. Nat Rev Dis Primers 3: 17009, 2017.

3. Bharthuar A, Pandey H and Sood S: Management of metastatic renal cell carcinoma-mini review. J Kidney Cancer VHL 2: $75-83,2015$

4. Teixeira AL, Dias F, Gomes M, Fernandes M and Medeiros R: Circulating biomarkers in renal cell carcinoma: The link between microRNAs and extracellular vesicles, where are we now? J Kidney Cancer VHL 1: 84-98, 2014.

5. Ljungberg B, Bensalah K, Canfield S, Dabestani S, Hofmann F, Hora M, Kuczyk MA, Lam T, Marconi L, Merseburger AS, et al: EAU guidelines on renal cell carcinoma: 2014 update. Eur Urol 67: 913-924, 2015.

6. Aguiari G: MicroRNAs in clear cell renal cell carcinoma: Biological functions and applications. J Kidney Cancer VHL 2: $140-152,2015$.

7. Ling H, Girnita L, Buda O and Calin GA: Non-coding RNAs: The cancer genome dark matter that matters! Clin Chem Lab Med 55: 705-714, 2017.

8. Liang T, Hu XY, Li YH, Tian BQ, Li ZW and Fu Q: MicroRNA-21 regulates the proliferation, differentiation, and apoptosis of human renal cell carcinoma cells by the mTOR-STAT3 signaling pathway. Oncol Res 24: 371-380, 2016.

9. Xiao H, Xiao W, Cao J, Li H, Guan W, Guo X, Chen K, Zheng T, Ye Z, Wang J and Xu H: miR-206 functions as a novel cell cycle regulator and tumor suppressor in clear-cell renal cell carcinoma. Cancer Lett 374: 107-116 2016.

10. Liu F, Chen N, Xiao R, Wang W and Pan Z: miR-144-3p serves as a tumor suppressor for renal cell carcinoma and inhibits its invasion and metastasis by targeting MAP3K8. Biochem Biophys Res Commun 480: 87-93, 2016.

11. Jeong JY, Kang H, Kim TH, Kim G, Heo JH, Kwon AY, Kim S, Jung SG and An HJ: MicroRNA-136 inhibits cancer stem cell activity and enhances the anti-tumor effect of paclitaxel against chemoresistant ovarian cancer cells by targeting Notch3. Cancer Lett 386: 168-178, 2017.

12. Yan M, Li X, Tong D, Han C, Zhao R, He Y and Jin X. miR-136 suppresses tumor invasion and metastasis by targeting RASAL2 in triple-negative breast cancer. Oncol Rep 36: 65-71, 2016.

13. Shen S, Yue H, Li Y, Qin J, Li K, Liu Y and Wang J: Upregulation of miR-136 in human non-small cell lung cancer cells promotes Erk1/2 activation by targeting PPP2R2A. Tumour Biol 35: 631-640, 2014

14. Livak KJ and Schmittgen TD: Analysis of relative gene expression data using real-time quantitative PCR and the 2(-Delta Delta C(T)) method. Methods 25: 402-408, 2001.

15. Dweep H, Sticht C, Pandey P and Gretz N: miRWalk-database: Prediction of possible miRNA binding sites by 'walking' the genes of three genomes. J Biomed Inform 44: 839-847, 2011.

16. Enright AJ, John B, Gaul U, Tuschl T, Sander C and Marks DS: MicroRNA targets in Drosophila. Genome Biol 5: R1, 2003.
17. Lewis BP, Burge CB and Bartel DP: Conserved seed pairing, often flanked by adenosines, indicates that thousands of human genes are microRNA targets. Cell 120: 15-20, 2005.

18. Kotlabova K, Doucha J and Hromadnikova I: Placental-specific microRNA in maternal circulation-identification of appropriate pregnancy-associated microRNAs with diagnostic potential. J Reprod Immunol 89:185-191, 2011.

19. Tusong H, Maolakuerban N, Guan J, Rexiati M, Wang WG, Azhati B, Nuerrula Y and Wang YJ: Functional analysis of serum microRNAs miR-21 and miR-106a in renal cell carcinoma. Cancer Biomarker 18: 79-85, 2017.

20. Yang Y, Liu L, Cai J, Wu J, Guan H, Zhu X, Yuan J, Chen S and Li M: Targeting Smad2 and Smad3 by miR-136 suppresses metastasis-associated traits of lung adenocarcinoma cells. Oncol Res 21: 345-352, 2013.

21. Mosakhani N, Pazzaglia L, Benassi MS, Borze I, Quattrini I, Picci P and Knuutila S: MicroRNA expression profiles in metastatic and non-metastatic giant cell tumor of bone. Histol Histopathol 28: 671-678, 2013.

22. Yang Y, Wu J, Guan H, Cai J, Fang L, Li J and Li M: MiR-136 promotes apoptosis of glioma cells by targeting AEG-1 and Bcl-2. FEBS Lett 586: 3608-3612, 2012.

23. Jeansonne D, Pacifici M, Lassak A, Reiss K, Russo G, Zabaleta J and Peruzzi F: Differential effects of MicroRNAs on glioblastoma growth and migration. Genes (Basel) 4: 46-64, 2013.

24. Zhao H, Liu S, Wang G, Wu X, Ding Y, Guo G, Jiang J and Cui S: Expression of miR-136 is associated with the primary cisplatin resistance of human epithelial ovarian cancer. Oncol Rep 33: 591-598, 2015.

25. Gao H, Song X, Kang T, Yan B, Feng L, Gao L, Ai L, Liu X, $\mathrm{Yu} \mathrm{J}$ and $\mathrm{Li} \mathrm{H}$ : Long noncoding RNA CRNDE functions as a competing endogenous RNA to promote metastasis and oxaliplatin resistance by sponging miR-136 in colorectal cancer. Onco Targets Ther 10: 205-216, 2017.

26. Hao JF, Ren KM, Bai JX, Wang SN, Shao B, Cao N and Li X: Identification of potential biomarkers for clear cell renal cell carcinoma based on microRNA-mRNA pathway relationships. J Cancer Res Ther 10 (Suppl): C167-C177, 2014.

27. Wu H, Liu Q, Cai T, Chen YD, Liao F and Wang ZF: MiR-136 modulates glioma cell sensitivity to temozolomide by targeting astrocyte elevated gene-1. Diagn Pathol 9: 173, 2014.

28. Chen W, Yang Y, Chen B, Lu P, Zhan L, Yu Q, Cao K and Li Q: MiR-136 targets E2F1 to reverse cisplatin chemosensitivity in glioma cells. J Neurooncol 120: 43-53, 2014.

29. Zhao J, Wang W, Huang Y, Wu J, Chen M, Cui P, Zhang W and Zhang Y: HBx elevates oncoprotein AEG-1 expression to promote cell migration by downregulating miR-375 and miR-136 in malignant hepatocytes. DNA Cell Biol 33: 715-722, 2014.

30. Ji L, Zhang L, Li Y, Guo L, Cao N, Bai Z, Song Y, Xu Z, Zhang J, Liu $\mathrm{C}$ and Ma X: MiR-136 contributes to pre-eclampsia through its effects on apoptosis and angiogenesis of mesenchymal stem cells. Placenta 50: 102-109, 2017.

31. Zhang D, Wang J, Wang Z, Zhang $T$, Shi P, Wang X, Zhao F, Liu X, Lin X and Pang X: miR-136 modulates TGF-beta1-induced proliferation arrest by targeting PPP2R 2A in keratinocytes. Biomed Res Int 2015: 453518, 2015.

32. Zhang CF, Kang K, Li XM and Xie BD: MicroRNA-136 promotes vascular muscle cell proliferation through the ERK1/2 pathway by targeting PPP2R2A in atherosclerosis. Curr Vasc Pharmacol 13: 405-412, 2015.

33. Zhang B, Pan X, Cobb GP and Anderson TA: microRNAs as oncogenes and tumor suppressors. Dev Biol 302: 1-12, 2007. 